\title{
MODELS FOR TECHNOLOGY PROGRAMMES WITHIN AN INTELLECTUAL PROPERTY MANAGEMENT SYSTEM
}

B.N. Korobets

\section{Bauman Moscow State Technical University, Moscow, Russian Federation}

\section{Keywords}

IP management system, result of intellectual activity, technology development programme, technology commercialisation

Received 09.09.2016

(c) Bauman Moscow State Technical University, 2016

Only $2 \%$ of protectable Results of Intellectual Activity (RIA) are currently traded in the Russian market. The percentage of knowledge-intensive products in Russian exports slightly exceeds $5 \%$, while imports of intellectual property are 11 times as high as exports [1]. Russia is among top five countries by the number of intellectual property products registered by RIA per year, but lags way behind other countries in the rating of high-tech exports.

The engineering research potential of the research and industrial sectors unlocked through a robust IP management system is an integral parameter of a country that determines its present and future place in the global economy [2], while engineering infrastructure is a predominant driving force behind Russia's technological advances [3].

For educational, scientific and industrial organisations to develop and efficiently generate new technologies, it is pivotal to adopt and put in place an intellectual property management system [4] that would, on the organisation level, help to build an efficient framework for using and commercialising research results.

However, it would be premature, and even impossible, to discuss implementation of an IP management system with there being no relevant and scientifically proven technology development programmes.

We would highlight three groups of research results that drive the engineering research potential of the Russian scientific and industrial sectors so as to identify the best models for building technology development programmes.

The first group covers the theoretical framework for engineering research represented by Results of Scientific and Technical Activity (RSTA) such as new concepts, principles, solutions, etc. 
The second group includes the results of research and development represented by intellectual property (RIA) listed in the Russian Civil Code.

The third group comprises standalone technologies consisting of results of intellectual activity.

We would note that each RSTA can be used in various research and development projects to produce new RIAs. In its turn, each RIA can be used to generate new technologies.

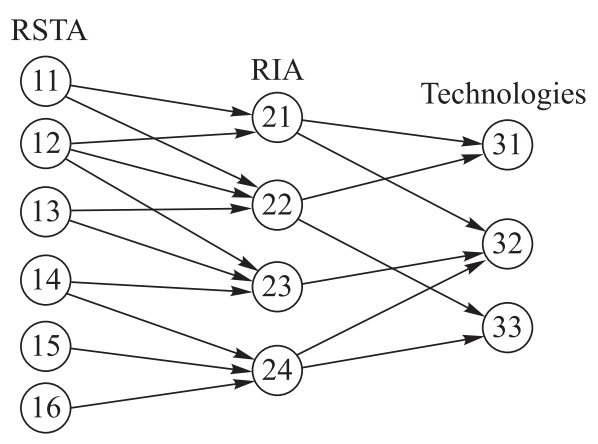

Fig. 1. Flow chart for new technology creation

Similarly, several RSTAs can be required to create an RIA, and several RIAs are necessary to create a technology. Figure 1 shows a flow chart for new technology creation.

Each circle in Figure 1 corresponds to a research result. Circle $(i, j)$ corresponds to the $j^{\text {th }}$ research result of the $i^{\text {th }}$ layer. Circles $(1, j)$ and $(2, k)$ are linked by arc $[(1, j),(2, k)]$ if the $j^{\text {th }}$ layer RSTA is used to develop the second layer $\mathrm{k}$. Circles $(2, j)$ and $(3, k)$ are linked by arc $[(2, j),(3, k)]$ if RIA $j$ is used to create technology $\mathrm{k}$.

Each research result (RSTA, RIA, technology) features four parameters:

- cost of creation $\left(c_{i j}\right)$;

- time of creation $\left(t_{i j}\right)$;

- risk of creation $\left(p_{i j}\right)$;

- research level $\left(w_{i j}\right)$.

Let's break down all types of technologies into $r$ groups (areas). $Q_{j}$ will mean a set of technologies of the $j^{\text {th }}$ area.

The following value

$$
W_{i}=\sum_{j \in Q_{i}} w_{i j}
$$

determines the research level (RL) of the $i^{\text {th }}$ technology area. We would then introduce a qualitative three-point RL scoring scale. To do this, we need to determine threshold levels $A_{i k}, k=1,2$. If $W_{i}=\sum_{j \in Q_{i}} w_{i j}$, then the $\mathrm{RL}$ is below the global level; if $A_{i 1} \leq W_{i}<A_{i 2}$, then the RL is at par with the global level. Finally, if $A_{i 2} \leq W_{i}$, then the $\mathrm{RL}$ is above the global level.

Let $q_{i}$ be the qualitative score of the RL for the $i^{\text {th }}$ technology area. To assess the RL of the technology area in general, we will introduce a comprehensive RL scoring system [5]. The system is a pair-wise aggregation of area scores based on matrix convolutions. Figure 2 provides an example of comprehensive scoring for four areas.

The comprehensive scoring system reflects the strategic priorities in technological development [6]. For instance, the lower left matrix (Fig. 2) implies that direction 1 has a certain development priority over direction 2. Indeed, if we assess directions 
$(2 ; 1)$, the total score will be 2 , and if we do a reverse assessment $(1 ; 2)$, it will be equal to 1 . Likewise, for directions $(3 ; 2)$ the total score will be 3 , and for directions $(2 ; 3)$, it is 2 . For the lower right matrix direction 4 has the priority, and for the upper one, both combined directions I and II have the same priority (a symmetric matrix).

\begin{tabular}{|c|c|c|c|c|c|c|c|c|c|}
\hline & & & & 3 & 1 & 1 & 3 & & \\
\hline & & & & 2 & 1 & 2 & 2 & & \\
\hline & & & & 1 & 1 & 1 & 2 & & \\
\hline & & & & $\mathrm{II} / \mathrm{I}$ & 1 & 2 & 3 & & \\
\hline 3 & 2 & 2 & 3 & & 3 & 2 & 2 & 3 & 3 \\
\hline 2 & 1 & 2 & 3 & & 2 & 2 & & 2 & 2 \\
\hline 1 & 1 & 2 & 2 & I & 1 & 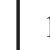 & 1 & 1 & 2 \\
\hline $2 / 1$ & 1 & 2 & 3 & & 4 & 3 & & 2 & 3 \\
\hline
\end{tabular}

Fig. 2. Example of comprehensive scoring for four areas

We also need to note that the number of levels in the scoring scale can be increased. This does not affect targets to be set in building a technological development programme and the ways to achieve them. The comprehensive score of the technology's RL is the principal criterion when developing such programmes.

Content-wise, what we need to do is to develop a technological development programme that would deliver the required RL, i. e. the required comprehensive score at minimum costs over a given period of time subject to risks.

As noted by some authors, there have been some cases in Russian research practice and industrial organisations when research programmes were built within an IP management system based on existing RIA owned by such organisations $[7,8]$.

In such case, we would only examine the third level in the structure shown in Fig. 1. We will not specify the level index further on. Let's have a look at the problem without taking risks into account. We have $n_{j}$ projects that can be included in the technological development programme, and $j=\overline{1, m}$, where $m$ is the number of areas.

We will first consider the programme's scope and decide how to determine it, i. e. which current projects are eligible to be included in the programme. As noted above, each project $i$ has implementation costs $c_{i}$ and research level $w_{i}$. Let $x_{i j}=1$, if project $i$ from area $j$ is included in the programme; otherwise, $x_{i j}=0$. With given $x_{i j}, i \in Q_{j}, j=\overline{1, m}$, we can determine the increase in the RL of each area $\Delta_{j}=\sum_{i} x_{i j} w_{i j}$ and, accordingly, the change in the score for each area, and, consequently, the change in the comprehensive score.

Then we need to determine $\left\{x_{i j}\right\}, i \in Q_{j}, j=\overline{1, m}$, that would deliver the required comprehensive score at minimum costs. 
The algorithm for solving this task comprises two stages. First, we need to determine minimum costs $s_{i j}$ required to achieve scores $j=1,2,3$ for each area $i$. If the existing score is equal to 1 , then $s_{i 1}$ represents the cost of maintaining the existing RL for this area (below we will assume that these costs are known).

Second, the resulting score $s_{i j}, j=\overline{1,3}, i=\overline{1, m}$, is used to achieve the required comprehensive score at minimum costs. Let us discuss the algorithms to solve these problems.

Stage I. At the first stage, solve $m$ problems (for each area). Describe the relevant problem, omitting the area index. Assume without loss of generality that the existing RL score is 1 (below the global level).

Determine the increase in the RL required to achieve scores 2 and 3. If the existing level is equal to $W^{0}<A_{1}$, then the required increases are:

$$
\begin{aligned}
& \Delta_{1}=A_{1}-W^{0} ; \\
& \Delta_{2}=A_{2}-W^{0} .
\end{aligned}
$$

Let $x_{i}=1$ if project I is included in the technological development programme for the area in question; otherwise, $x_{i}=0$. Let us examine the following problem:

$$
\sum_{i} x_{i} c_{i} \rightarrow \min
$$

with the following limitation

$$
\sum_{i} x_{i} w_{i} \geq \Delta_{2}
$$

This is a classic knapsack problem that has efficient solutions for integer-valued parameters (e. g. dichotomic programming [9]).

Note that the solution to problem (1), (2) with the right-hand side equal to $\Delta_{2}$ also provides for optimal solutions at smaller values of the right-hand side, specifically at $\Delta_{1}$. Therefore, by solving the problem, we will get minimum costs $s_{2}$ and $s_{3}$ (as noted above, costs $s_{1}$ are assumed to be known).

Examine the following example. There are five projects nominated to be included in the technological development programme. Their data are given below:

$\begin{array}{llllll}i \ldots \ldots . & 1 & 2 & 3 & 4 & 5 \\ s_{i} \ldots \ldots . & 3 & 4 & 5 & 4 & 6 \\ w_{i} \ldots \ldots & 7 & 6 & 5 & 7 & 8\end{array}$

Let $A_{1}=30, A_{2}=40$, and $W^{0}=15$. Therefore, $\Delta_{1}=15, \Delta_{2}=25$. Problem

$$
3 x_{1}+4 x_{2}+5 x_{3}+4 x_{4}+6 x_{5} \rightarrow \min
$$

with the following limitation

$$
7 x_{1}+6 x_{2}+5 x_{3}+6 x_{4}+8 x_{5} \geq 25 \text {. }
$$


Take the structure of dichotomic representation of the problem in the form shown in Fig. 3.

Fig. 3. Structure of dichotomic representation of the problem

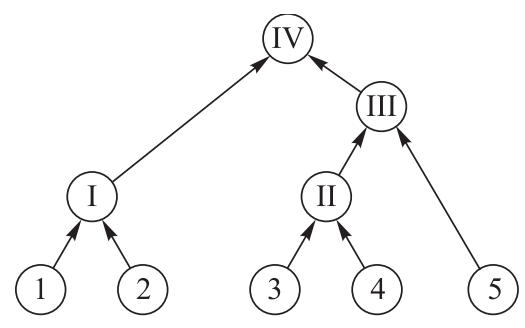

Step 1. Take projects 1 and 2. The solution is given in the Table 1 below.

Table 1

\begin{tabular}{|c|c|c|}
\hline 1 & $(4 ; 6)$ & $(7 ; 13)$ \\
\hline 0 & 0 & $(3 ; 7)$ \\
\hline $2 / 1$ & 0 & 1 \\
\hline
\end{tabular}

The first number in the boxes represents costs, and the second, the RL. Exclude option $(4 ; 6)$, as it is dominated by option $(3 ; 7)$ by providing a larger RL at lower costs. The results (combined project I) are summarised below:

$\begin{array}{llll}\text { Option ........ } & 0 & 1 & 2 \\ \text { Costs .......... } & 0 & 3 & 7 \\ \text { RL ............. } & 0 & 7 & 13\end{array}$

Step 2. Take projects 3 and 4 . The solution is given in the Table 2 below.

\section{Table 2}

\section{The solution}

\begin{tabular}{|c|c|c|}
\hline 1 & $(4 ; 7)$ & $(9 ; 12)$ \\
\hline 0 & 0 & $(5 ; 5)$ \\
\hline $4 / 3$ & 0 & 1 \\
\hline
\end{tabular}

Exclude option $(5 ; 5)$ as it is dominated by option $(4 ; 7)$. The results (combined project II) are summarised below:

$\begin{array}{llll}\text { Option ........ } & 0 & 1 & 2 \\ \text { Costs .......... } & 0 & 4 & 9 \\ \text { RL ............ } & 0 & 7 & 12\end{array}$

Step 3. Take combined project II and project 5. The solution is given in the Table 3 below.

Table 3

\section{The solution}

\begin{tabular}{|c|c|c|c|}
\hline 1 & $(6 ; 8)$ & $(10 ; 15)$ & $(15 ; 20)$ \\
\hline 0 & 0 & $(4 ; 7)$ & $(9 ; 12)$ \\
\hline $5 /$ II & 0 & 1 & 2 \\
\hline
\end{tabular}


The results (combined project III) are summarised below:

$\begin{array}{lllllll}\text { Option ....... } & 0 & 1 & 2 & 3 & 4 & 5 \\ \text { Costs ......... } & 0 & 4 & 6 & 9 & 10 & 15 \\ \text { RL ............ } & 0 & 7 & 8 & 12 & 15 & 20\end{array}$

Step 4. Take combined projects I and III. The solution is given in the Table 4.

Table 4

The solution

\begin{tabular}{|c|c|c|c|c|c|c|}
\hline 2 & $(7 ; 13)$ & $(11 ; 20)$ & $(13 ; 21)$ & $(16 ; 25)$ & - & - \\
\hline 1 & $(3 ; 7)$ & $(7 ; 14)$ & $(9 ; 15)$ & $(12 ; 19)$ & $(13 ; 22)$ & $(18 ; 27)$ \\
\hline 0 & 0 & $(4 ; 7)$ & $(6 ; 8)$ & $(9 ; 12)$ & $(10 ; 15)$ & $(15 ; 20)$ \\
\hline I / III & 0 & 1 & 2 & 3 & 4 & 5 \\
\hline
\end{tabular}

In the Table 4, find a box with the lowest first number out of the boxes where the second number is higher than, or equal to, $\Delta_{2}=25$. It is box $(16 ; 25)$ with costs equal to 16 ; accordingly, $s_{3}=16$.

To determine $s_{2}$, find a box with the lowest first number out of the boxes where the second number is higher than, or equal to, $\Delta_{1}=15$. It is box $(9 ; 15)$ with costs equal to $s_{2}=9$.

Find the solutions, i. e. the eligible projects, using the backward algorithm [10]. Box $(16 ; 25)$ corresponds to option 2 in the combined project I Table 4, i. e. inclusion of projects 1 and 2 into the programme, and option 3 of the combined project III table 4. Option 3 of the combined project III Table 4 corresponds to option 2 of the combined project II Table 3, i. e. inclusion of projects 3 and 4 into the programme. Therefore, to achieve score 3 , we need to include projects $1,2,3$ and 4 in the programme.

Do the same to determine the eligible projects to get score 2 . Box $(9 ; 15)$ corresponds to option 1 of the combined project I table 4, i. e. inclusion of project 1 into the programme, and option 2 of the combined project III Table 4, i. e. inclusion of project 5 into the programme.

Stage II. By solving $m$ problems of Stage I, we got a table of minimum costs $\left(s_{i j}\right)$ required to achieve (maintain) comprehensive scores 1, 2 and 3 (Table 5). Since potential approaches to solving Stage II problems are mentioned in [11], we would only discuss one of the options through the example of a comprehensive scoring system from Fig. 2.

Table 5

A table of minimum costs $s_{i j}$

\begin{tabular}{|c|c|c|c|c|}
\hline \multirow{2}{*}{$j$} & \multicolumn{4}{|c|}{$i$} \\
\cline { 2 - 5 } & 1 & 2 & 3 & 4 \\
\hline 1 & 5 & 4 & 7 & 3 \\
\hline 2 & 16 & 10 & 13 & 9 \\
\hline 3 & 25 & 20 & 21 & 18 \\
\hline
\end{tabular}


Step 1. Take the lower left matrix. Add the second number to matrix boxes: costs $s_{1 j}$ and $s_{2 j}$ (Table 6).

\section{Table 6}

The lower left matrix

\begin{tabular}{|l|l|l|l|}
\hline$(3 ; 20)$ & $(2 ; 25)$ & $(2 ; 36)$ & $(3 ; 45)$ \\
\hline$(2 ; 10)$ & $(1 ; 15)$ & $(2 ; 26)$ & $(3 ; 35)$ \\
\hline$(1 ; 4)$ & $(1 ; 9)$ & $(2 ; 20)$ & $(2 ; 29)$ \\
\hline $2 / 1$ & $(1 ; 5)$ & $(2 ; 16)$ & $(3 ; 25)$ \\
\hline
\end{tabular}

The principal rule of optimisation: choose the box with the lowest second number out of all boxes with the same first number. The result is: $s_{\mathrm{II} 1}=9 ; s_{\mathrm{II} 2}=20 ; s_{\mathrm{II} 3}=35$.

Step 2. Take the lower right matrix (Table 7).

\section{Table 7}

The lower right matrix

\begin{tabular}{|c|c|c|c|}
\hline$(3 ; 18)$ & $(2 ; 25)$ & $(3 ; 31)$ & $(3 ; 39)$ \\
\hline$(2 ; 9)$ & $(2 ; 16)$ & $(2 ; 22)$ & $(2 ; 30)$ \\
\hline$(1 ; 3)$ & $(1 ; 10)$ & $(1 ; 16)$ & $(2 ; 24)$ \\
\hline $4 / 3$ & $(1 ; 7)$ & $(2 ; 13)$ & $(3 ; 21)$ \\
\hline
\end{tabular}

The result is: $s_{11}=10 ; s_{12}=16 ; s_{13}=31$.

Step 3. Take the upper matrix (Table 8). The result is: $s_{1}=19 ; s_{2}=36 ; s_{3}=66$.

Table 8

The upper matrix

\begin{tabular}{|c|c|c|c|}
\hline$(3 ; 35)$ & $(2 ; 45)$ & $(2 ; 51)$ & $(3 ; 66)$ \\
\hline$(2 ; 20)$ & $(1 ; 30)$ & $(2 ; 36)$ & $(2 ; 51)$ \\
\hline$(1 ; 9)$ & $(1 ; 19)$ & $(1 ; 25)$ & $(2 ; 40)$ \\
\hline II / I & $(1 ; 10)$ & $(2 ; 16)$ & $(3 ; 31)$ \\
\hline
\end{tabular}

Note that to get comprehensive score 2, we need 36 units of costs. The relevant option of the programme, i. e. the required RL scores for each area are also determined using the backward algorithm. The optimal option corresponds to box $(2 ; 36)$ of Step 3, i. e. box $(2 ; 16)$ of Step 2 and box $(2 ; 20)$ of Step 1. In their turn, these boxes correspond to score 2 for the first area, 1 for the second area, 1 for the third area, and 2 for the fourth area.

Thus, in this case the optimal strategy is to upgrade areas 1 and 4 to the global level. To get comprehensive score 3 we need 66 units, which corresponds to score 2 for the first area, score 3 for the second area, score 2 for the third area, and score 3 for the fourth area.

Conclusion. The conclusion that we can draw here is that by modelling its technology development programmes an organisation is able to drastically cut down its 
costs of planning R\&D, defining the terms of reference for future RIAs, and rolling out new technologies. This exercise is equally important for efficient operation of an IP management system as organisations can integrate these models into their decision-making processes in managing their intellectual property.

\section{REFERENCES}

[1] http://www.council.gov.ru/structure/docs/31035/

[2] Chereshnev V.A. The institutional and legal conditions for the formation of the innovative environment for economic modernization. Innovatsii [Innovation], 2010, no. 5, pp. 37-42 (in Russ.).

[3] Amelina K.E., Burenina V.I. State regulation of innovative activity. Vestnik Tverskogo gos. universiteta. Ser.: Pravo [Vestnik of Tver State University. Series: Right], 2012, no. 32, pp. 7-14 (in Russ.).

[4] Van Caenegem W. Intellectual property law and innovation. N.Y., Cambridge University Press, 2007.

[5] Burkov V.N., Burkova I.V. The principle of coordinated planning in control of social and ecological-economic systems. Game Theory and Applications, 2015, vol. 17, pp. 17-36.

[6] Jothi Arul. Strategic management of intellectual property issues in research collaboration. 3rd Annual International Conference on Business Strategy and Organizational Behaviour. Malaysia, 2011.

[7] Gorodilova U.L. To the question on perfection of legal regulation of activity state and municipal institutions. Moskovskoye nauchnoye obozreniye, 2011, iss. 10, no. 45. Available at: http://www.ingnpublishing.com/journal/1/2011/10_14_oktyabr/gorodilova/

[8] Amelina K.E., Korobets B.N. Algorithmic management of the organization as a method of increasing the coefficient of efficiency of its activity. Nauka i biznes: puti razvitiya [Science and business: ways of development], 2015, no. 10, pp. 24-26 (in Russ.).

[9] Burkov V.N., Burkova I.V., Popov M.V. A method of dichotomous programming. Upravlenie bol'shimi sistemami: sb. tr. [Large-Scale Systems Control], 2004, iss. 9, pp. 57-75.

Available at: http://ubs.mtas.ru/archive/search_results_new.php?publication_id=2899

[10] Minaev V.A. Interval estimations of the prime numbers amount. The 8th Congress of the International Society for Analysis, its Applications, and Computation Abstracts, 2011.

[11] Burkov V.N., Enaleev A.K., Novikov D.A. Probabilistic stimulation problem. Automation and Remote Control, 1993, iss. 12, pp. 1846-1851.

Korobets B.N. - Cand. Sci. (Jur.), Assoc. Professor, Head of Law, Intellectual Property and Forensic Examination Department, Director of the Center for Intellectual Property Protection, Bauman Moscow State Technical University (2-ya Baumanskaya ul. 5, Moscow, 105005 Russian Federation).

\section{Please cite this article in English as:}

Korobets B.N. Models for Technology Programmes within an Intellectual Property Management System. Vestn. Mosk. Gos. Tekh. Univ. im. N.E. Baumana, Estestv. Nauki [Herald of the Bauman Moscow State Tech. Univ., Nat. Sci.], 2016, no. 6, pp. 135-142.

DOI: 10.18698/1812-3368-2016-6-135-142 